\title{
Olimpíada de Raciocínio Lógico: relatos de uma competição para alunos ingressantes em curso de nível superior
}

\author{
Sérgio Luis Antonello ${ }^{1,2}$, Rogério Cardoso ${ }^{1}$ \\ ${ }^{1}$ Centro Universitário Hermínio Ometto (FHO-UNIARARAS) \\ Av. Dr. Maximiliano Baruto, 500 - Jd. Universitário - Araras - SP CEP: 13607-339 \\ ${ }^{2}$ Universidade Estadual Paulista “Júlio de Mesquita Filho" (UNESP) \\ Av. 24-A, 1515 - Bela Vista - Rio Claro - SP CEP: 13506-900 \\ \{antonello.sergioluis, prof.rogeriocardoso\}egmail.com
}

\begin{abstract}
This paper describes the Logical Thinking Olympiad, an event that aims mainly for freshman students of Bachelor of Information Systems, and has been collaborating on two important points. First it contributes to the disciplines such as algorithms and programming language for a primary analysis of how the student makes use of logic. Second because it facilitates the integration of students of the course itself as well as those from other courses.
\end{abstract}

Resumo. Este artigo descreve a Olimpiada de Raciocínio Lógico, um evento voltado, principalmente, para alunos ingressantes de um curso de Bacharelado em Sistemas de Informação, e que vem colaborando em dois pontos importantes. Primeiro contribui com disciplinas, como Algoritmos e Linguagem de Programação, para uma análise primária de como o aluno faz uso da lógica. Segundo porque facilita a integração entre alunos do próprio curso, bem como destes com alunos de outros cursos.

\section{Introdução}

A sociedade brasileira tem experimentado um importante movimento de acesso a Educação Superior, em que anualmente ocorrem milhares de matrículas de alunos em Instituições de Ensino Superior por todo o país. Em muitos casos, esses alunos são os primeiros representantes de suas famílias a ingressar em um curso superior.

Em cursos da área de Computação como Bacharelado em Sistemas de Informação, a disciplina de algoritmos, ministrada no início do curso, é considerada a base de apoio de outras disciplinas do curso e busca apresentar os princípios da lógica de programação e por meio dela, desenvolver nos alunos a capacidade de análise e resolução de problemas para desenvolvimento de programas.

Porém, tanto nas disciplinas de algoritmos quanto nas de linguagem de programação, pode ser computada uma quantidade relevante de reprovações, que dentre outros motivos, está à dificuldade em desenvolver a lógica de programação. Esse fator 
também acaba por ser representativo na evasão de alunos nos anos iniciais desses cursos. Segundo Deters et al. (2008) as disciplinas de algoritmos e programação, que normalmente são lecionadas nas primeiras fases dos cursos, são consideradas desafiadoras pelos alunos já que necessitam da aplicação lógico-matemática na solução de problemas.

Por outro lado, pode ser observado que jogos de vídeo games e computadores conquistaram um espaço importante na vida dos atuais alunos ingressantes nos cursos superiores, e que muitos desses jovens são seduzidos e ficam emprenhados nos desafios que os jogos oferecem (Savil; Ulbricht, 2008). Pensando nesse potencial, busca-se meios de desviar e atrair para atividades educacionais, a mesma atenção que os estudantes dão aos jogos, e nesse intuito, surge à proposta da Olimpíada de Raciocínio Lógico (ORL).

O modelo da ORL foi inspirado na Maratona de Programação e na Olimpíada Brasileira de Informática (OBI), ambas promovidas pela Sociedade Brasileira de Computação (SBC).

Aberta para alunos ingressantes dos cursos de Sistemas de Informação, Administração, Ciências Contábeis e Ciências Econômicas, a ORL tem objetivos que atendem a requisitos primários desses cursos. No caso específico da área da computação, dentre outras coisas, a ORL permite uma primeira análise dos alunos de Sistema de Informação em relação ao uso de lógica, fundamental em algoritmos e linguagens de programação.

\section{Competições}

A competitividade é uma prática que pode ser adotada como estratégia para estimular o maior esforço dos alunos no aprendizado de determinados conteúdos. Dessa forma, alunos de todos os níveis educacionais podem participar de olimpíadas de conhecimento em várias áreas.

As competições escolares são estratégias pedagógicas que podem auxiliar na aprendizagem dos estudantes, já que nesse tipo de atividade o aluno tem a oportunidade de construir, analisar e compartilhar o conhecimento, além de permear outras questões como trabalhar a ansiedade, desenvolver a autonomia e melhorar a capacidade de atenção e a concentração (Lopes, 2005).

Associando as ideias de Tarouco et al. (2004) as competições podem ser usadas como instrumentos no ensino, uma vez que têm características de motivação, diversão e de exercitar as funções mentais e intelectuais dos competidores, e como consequência, facilitar o aprendizado e aumentar a capacidade de retenção de novos conteúdos ensinados. Também, possibilita explorar a autonomia, a criatividade e a simulação novas situações bem como de situações já conhecidas.

No Brasil, ocorrem, anualmente, importantes competições para alunos do ensino fundamental, médio e superior, como a Olimpíada Brasileira de Astronomia e Astronáutica, a Olimpíada Brasileira de Matemática, a Olimpíada Brasileira de Física, a Olimpíada Brasileira de Robótica, a Olimpíada de Língua Portuguesa, e a Olimpíada Brasileira de Biologia, dentre outras. Das competições na área da computação, 
destacam-se duas de iniciativa da Sociedade Brasileira de Computação (SBC), a Olimpíada Brasileira de Informática e a Maratona de Programação.

A Olimpíada Brasileira de Informática (OBI) tem como objetivos estimular o interesse pela computação e por ciências em geral, promover a introdução de disciplinas de técnicas de programação de computadores nas escolas de ensino médio e fundamental, proporcionar novos desafios aos estudantes e identificar talentos e vocações em ciência da computação de forma a melhor instruí-los e incentivá-los a seguir carreiras nas áreas de ciência e tecnologia. De acordo com o regulamento de 2015, cada competidor pode se inscrever em apenas uma das três modalidades existentes. Modalidade Iniciação, onde as tarefas das provas versam sobre problemas de lógica e problemas de computação, mas sem o uso de computador. Modalidade Programação, com tarefas sobre problemas de programação, com uso de computador, exigindo conhecimentos de estruturas de dados e técnicas de programação. Modalidade Universitária, composta por tarefas sobre problemas de programação, com uso de computador, e que também exige conhecimentos de estruturas de dados e técnicas de programação (UNICAMP, 2015).

A Maratona de Programação é parte da regional sul-americana do concurso ACM International Collegiate Programming Contest e se destina a alunos de cursos de graduação e início de pós-graduação na área de Computação e áreas afins. Busca promover nos alunos a criatividade, a capacidade de trabalho em equipe, a busca de novas soluções de software e a habilidade de resolver problemas estando sob pressão (USP, 2015).

Por fim, pode-se destacar que esse tipo de competição tem outros pontos positivos. Os alunos participantes acabam por criar novos vínculos com a instituição de ensino, constroem uma nova visão a respeito das disciplinas temas da competição e tem a oportunidade de interagirem fora da sala de aula com outros alunos e professores (Barros et al, 2009).

\section{OLIMPÍADA DE RACIOCÍNIO LÓGICO}

A Olimpíada de Raciocínio Lógico (ORL) iniciou-se em 2011 como um evento para todos os alunos do curso de Sistemas de Informação de uma Instituição de Ensino Superior.

Dentre seus objetivos estão proporcionar desafios aos alunos da instituição, proporcionar a oportunidade de aprender na prática, promover entre os alunos o estudo da lógica buscando incrementar o interesse dos mesmos por este tema, estimular à capacidade de resolver problemas, desenvolver as capacidades de observação e concentração e identificar talentos e motivá-los dentro da área de interesse. Outros dois objetivos são propostos para atender o curso de Sistemas de Informação. Primeiro pretende-se identificar o grau de afinidade dos alunos com o uso de lógica, essencial para várias disciplinas do curso, entre elas algoritmos e linguagens de programação. $\mathrm{O}$ segundo refere-se à socialização e integração do aluno de Sistemas de Informação com alunos do próprio curso e com alunos dos demais cursos do núcleo de negócios desta instituição de ensino. 


\section{CBIE-LACLO 2015}

Anais dos Workshops do IV Congresso Brasileiro de Informática na Educação (CBIE 2015)

Inspirada nos moldes da Maratona de Programação, na concepção original foi caracterizada como uma atividade prática organizada por professores interessados no desenvolvimento de habilidades de lógica em seus alunos, reforçando ou complementando conceitos de suas disciplinas.

Assim, na ORL devem ser realizadas atividades que busquem desenvolver o raciocínio lógico dos participantes, ao mesmo tempo em que estimulem sua memória e sua capacidade de solucionar problemas.

Com exceção da primeira edição que teve 13 problemas, a ORL se caracteriza por uma prova composta de 10 problemas. Um problema pode ter um único elemento a ser solucionado ou pode ser subdividido em várias partes, identificadas como itens a serem solucionados. A prova é elaborada por uma equipe de professores e contém problemas distribuídos em níveis fácil, médio e difícil e que podem ser dos tipos sudoku, kendoku, jogo simulando a organização de palitos de fósforos, enigma, de correlacionamento, de sucessões lógicas (sucessões com números, letras, palavras, imagens etc.), para uso de tabela verdade, para uso de conectivos, dentre outros.

Para participar da Olimpíada o aluno deve se inscrever em uma equipe composta por três elementos. Em data, local e horário pré-determinado pela coordenação do evento a equipe se apresenta para a realização da prova. As equipes devem ser distribuídas em espaço físico de tal forma que uma não interfira no desenvolvimento das atividades das outras equipes.

Um software para gerenciamento da ORL foi desenvolvido em 2013. Dentre outros benefícios, este software possibilita que a prova possa ser realizada simultaneamente em várias salas ou espaços físicos independentes, sendo que em cada uma deve haver um coordenador de sala, uma equipe de juízes e uma equipe de apoio.

Antes do início da competição, as equipes recebem um caderno de instruções e um caderno lacrado com os problemas da prova. Os únicos materiais permitidos durante a prova são o caderno de problemas, lápis, caneta e borracha. Não é permitido o uso de equipamentos eletrônicos, realizar consultas a qualquer tipo de material, analógico ou digital, nem a comunicação entre alunos de equipes diferentes.

O início da prova é sincronizado em todas as salas, momento em que é iniciada a contagem de tempo através de um cronômetro e momento em que as equipes podem abrir o caderno de problemas.

Vence a Olimpíada a equipe que resolver corretamente, segundo a comissão julgadora, a maior quantidade de problemas. Para o desempate de equipes com o mesmo número de problemas resolvidos, é considerada melhor colocada aquela equipe com menor Tempo Relativo (TR).

O TR é calculado de acordo com a Equação 1, descrita da seguinte forma: é a somatória dos tempos cronometrados e das punições para cada problema submetido e julgado correto, ou seja, toda vez que a equipe submete uma solução correta, será acrescido dois valores ao seu TR. O primeiro valor corresponde ao tempo registrado no cronômetro no exato momento em que o problema foi submetido aos juízes, enquanto que o segundo valor corresponde as punições de tempo para submissões deste problemas que foram julgadas incorretas. Cada punição representa 10 minutos no TR. 


\section{CBIE-LACLO 2015}

Anais dos Workshops do IV Congresso Brasileiro de Informática na Educação (CBIE 2015)

$$
T R=\sum_{i=1}^{10}\left(T C_{i}+P_{i} * 10\right)
$$

onde:

$\mathrm{TR}=$ tempo relativo da equipe;

$\mathrm{TC}=$ tempo do cronometro no exato momento que o problema foi submetido;

$\mathrm{P}$ = quantidade de punições por submissões do problema com solução incorreta.

Desta forma, cada problema ao ser finalizado deve ser imediatamente entregue, por meio da equipe de apoio, à comissão de julgamento. Se o problema estiver correto, computa-se para a equipe o tempo do cronômetro no ato do encaminhamento do problema ao julgamento. Porém, se o problema estiver errado, o mesmo será devolvido à equipe para nova tentativa. Cada tentativa errada pode acarretar punição de 10 minutos ao tempo relativo da equipe.

A tabela de classificação (Figura 1) é exibida em tempo real em todas as salas e mostra o tempo do cronômetro e a classificação geral da competição neste momento. Cada equipe tem seus resultados representados em uma linha da tabela. A primeira coluna mostra a posição da equipe na classificação da prova. A última coluna exibe a quantidade de problemas resolvidos corretamente e o respectivo tempo relativo. A segunda coluna identifica a equipe pelo nome. As demais colunas intermediárias possuem dados dos problemas de 1 a 10 , com as respectivas quantidades de submissões realizadas e o tempo do cronômetro para a submissão correta.

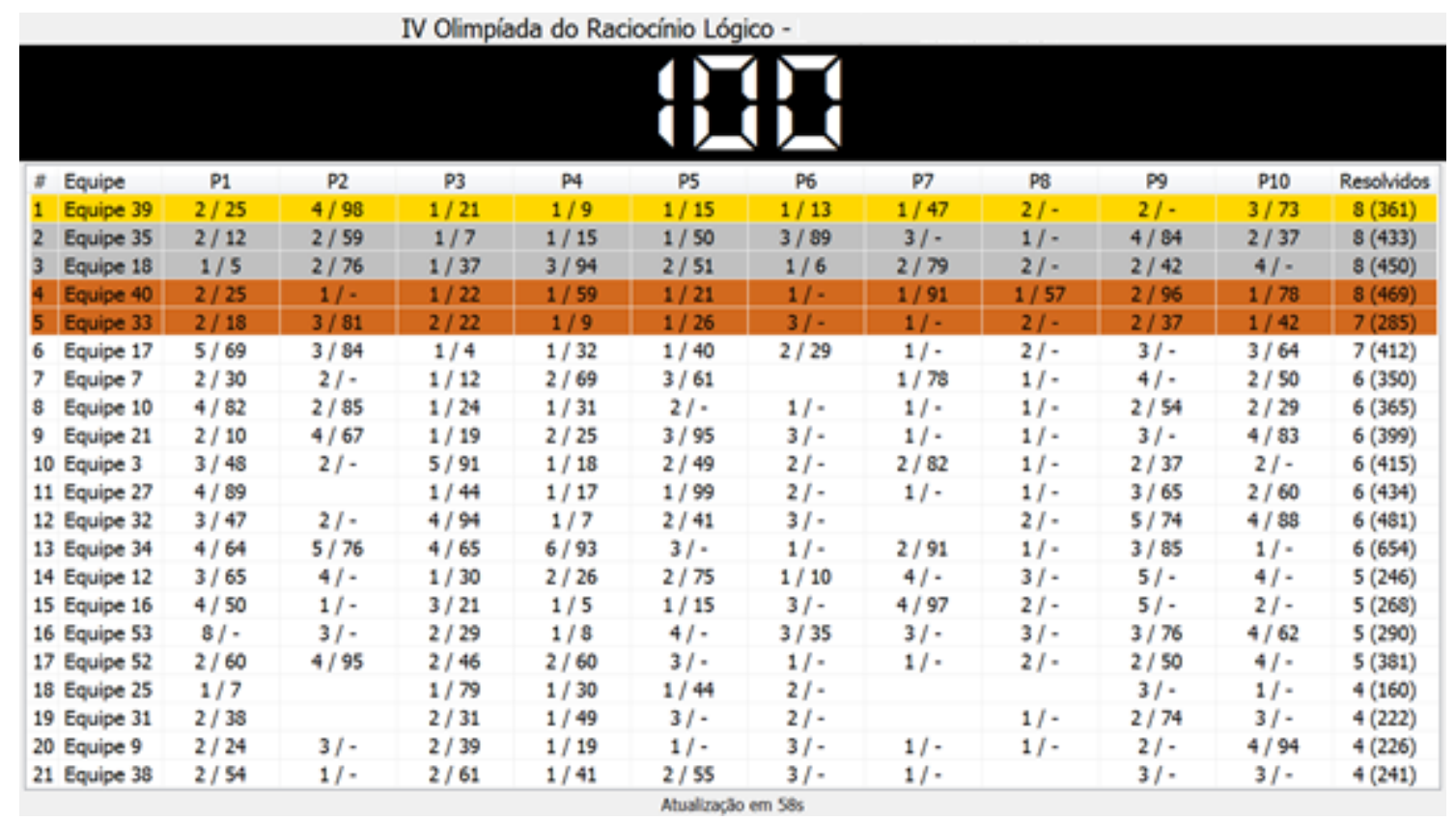

Figura 1. Tabela de classificação, no tempo 100 minutos, da IV ORL.

A equipe mais acima na tabela é a melhor classificada naquele momento específico, enquanto que as equipes mais abaixo apresentam as de piores resultados. Faltando 20 minutos para o término da prova, a classificação exibida para os 
competidores se congela. Isso acaba por gerar um clima que contribui em dois sentidos. Primeiro que todas as equipes acabam por se empenhar mais para galgar posições e segundo, para aquelas melhores classificadas, sentem que não devem se acomodar, o que poderia gerar perda de posições.

A premiação por meio de medalhas ocorre para as cinco equipes primeiras colocadas ao término da prova. Os integrantes da equipe mais bem colocada recebem medalhas de ouro. Já os integrantes das equipes que ficaram em segundo e terceiro lugares recebem medalhas de prata, enquanto que os integrantes das equipes da quarta $\mathrm{e}$ quinta posições recebem medalhas de bronze.

\section{Resultados}

A organização de um evento como a ORL segue uma agenda de atividades que se inicia na definição do coordenador geral, na escolha da comissão de prova e comissão julgadora, como seus respectivos coordenadores, na definição das datas importantes, na revisão e validação das regras, na divulgação do evento, na montagem da prova, na montagem de equipe de apoio para o dia do evento, e na realização da prova e na divulgação dos resultados.

A coordenação de prova faz uma chamada para o recebimento de questões, que são avaliadas e se aprovadas entram na composição da prova. Após a montagem da prova, esta é submetida a todos os membros da comissão para apreciação e julgamento. Questões aprovadas e não usadas em uma edição, vão para o banco de questões e podem ser usadas em edições posteriores da ORL.

A primeira edição da ORL, ocorrida em 2011, foi planejada para atender a todos os alunos do curso de Bacharelado em Sistemas de Informação. Embora tenha sido bem aceita por alunos dos quatro anos do curso, após a avaliação dos resultados, a comissão organizadora entendeu que pelos objetivos traçados, pelos resultados gerados e pelo feedback dos alunos, o foco deveria ser os alunos ingressantes do curso, fato ocorrido a partir da segunda edição em 2012.

Com o pleno sucesso entre os alunos ingressantes da edição de 2012 e buscando ampliar a socialização com alunos de outros cursos, a ORL foi aberta para que alunos do núcleo de negócios também participassem. Dessa forma, a partir da terceira edição em 2013, além dos alunos de Sistemas de Informação, inscreveram-se ingressantes dos cursos de Administração e Ciências Contábeis, e desde 2014, também participaram alunos do curso de Ciências Econômicas.

Durante a prova as equipes podem adotar estratégias diferentes, dependendo das características dos competidores, do tempo decorrido ou do problema em questão. A Figura 2 apresenta equipes nas quais seus participantes trabalham individualmente (Figura 2a) ou em conjunto (Figura $2 b$ ).

O número de equipes varia de acordo com o número de alunos participantes na ORL. Cada equipe tem três alunos e é incentivado que cada um dos integrantes seja de um curso diferente. A Tabela 1 apresenta um resumo dos dados referentes às cinco edições da ORL realizadas até o momento. 


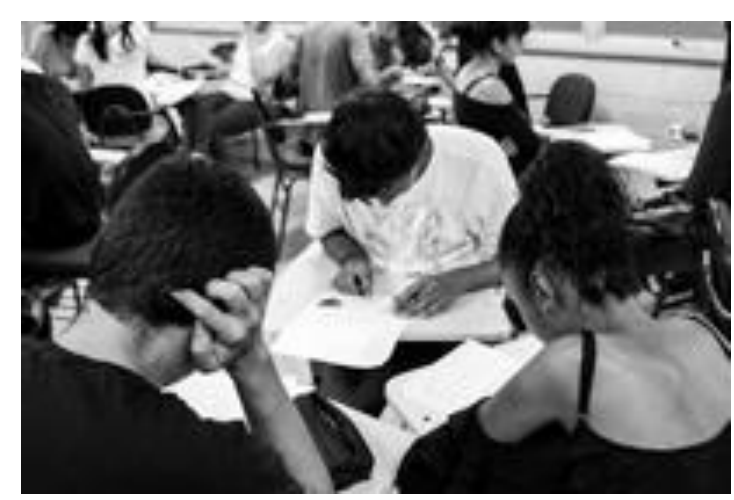

Figura 2a. Trabalho individual.

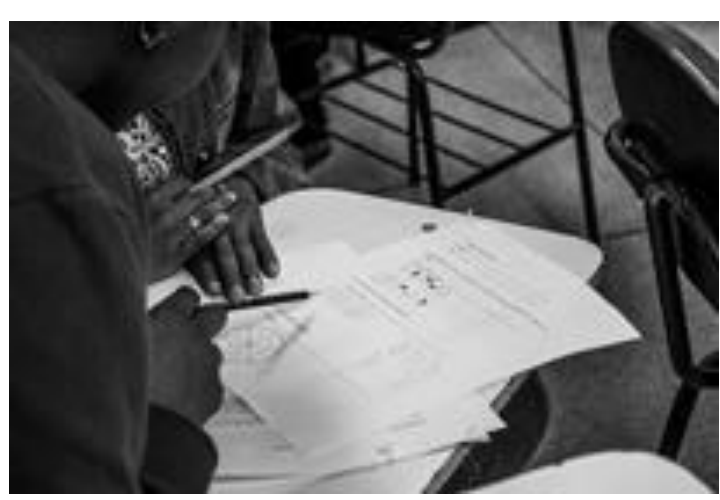

Figura 2b. Trabalho em conjunto.

Na segunda coluna pode-se observar o número de problemas propostos em cada prova, a partir de 2012 ficou estabelecido que a prova devesse ter 10 problemas. De acordo com o tipo bem como sua classificação em fácil, médio ou difícil, um problema pode ser subdividido em itens independentes. Dessa forma, um problema pode ter um ou vários itens a serem resolvidos. Um problema com mais de um item só será julgado como resolvido quando todos seus itens forem respondidos corretamente.

Tabela 1. Dados das cinco primeiras edições da Olimpíada de Raciocínio Lógico.

\begin{tabular}{|c|c|c|c|l|}
\hline $\begin{array}{c}\text { Edição - } \\
\text { Ano }\end{array}$ & $\begin{array}{c}\text { Problemas } \\
\text { - Itens }\end{array}$ & $\begin{array}{c}\text { Total de } \\
\text { Participantes }\end{array}$ & Equipes & \multicolumn{1}{|c|}{ Origem dos participantes } \\
\hline $1^{\mathrm{a}}-2011$ & $13-16$ & 84 & 27 & $\begin{array}{l}\text { Alunos do curso de Sistemas de } \\
\text { Informação }\left(1^{\circ} \text { ao } 4^{\text {o }} \text { ano }\right)\end{array}$ \\
\hline $2^{\mathrm{a}}-2012$ & $10-22$ & 28 & 10 & $\begin{array}{l}\text { Alunos ingressantes do curso de } \\
\text { Sistemas de Informação }\end{array}$ \\
\hline $3^{\mathrm{a}}-2013$ & $10-26$ & 59 & 21 & $\begin{array}{l}\text { Alunos ingressantes dos cursos de } \\
\text { Sistemas de Informação, Ciências } \\
\text { Contábeis e Administração. }\end{array}$ \\
\hline $4^{\mathrm{a}}-2014$ & $10-30$ & 159 & 53 & $\begin{array}{l}\text { Alunos ingressantes dos cursos de } \\
\text { Sistemas de Informação, Ciências } \\
\text { Contábeis, Ciências Econômicas e } \\
\text { Administração. }\end{array}$ \\
\hline $5^{\mathrm{a}}-2015$ & $10-27$ & 168 & 56 & $\begin{array}{l}\text { Alunos ingressantes dos cursos de } \\
\text { Sistemas de Informação, Ciências } \\
\text { Contábeis, Ciências Econômicas e } \\
\text { Administração. }\end{array}$ \\
\hline
\end{tabular}




\section{Considerações finais}

Cada edição da Olímpiada de Raciocínio Lógico mostra evolução na forma com que os objetivos propostos têm sido alcançados. A análise dos resultados de cada prova possibilita um perfil preliminar dos alunos do Curso de Sistema de Informação no que diz respeito ao raciocínio lógico que é fundamental em várias disciplinas do curso.

A participação na ORL possibilita a quebra de barreiras como timidez e insegurança, é uma oportunidade de integração entre alunos do próprio curso de Sistema de Informação bem como com alunos dos cursos da área de negócios da instituição. Essa integração torna-se mais significativa se for levado em consideração que os profissionais da área de negócios correspondem a potenciais clientes dos egressos de Sistemas de Informação.

Outros pontos positivos foram alcançados com a ORL. Pode-se destacar que o aluno ingressante é estimulado a resolver problemas e torna-se mais confiante diante dos desafios que o curso lhe colocará durante sua vida acadêmica. No curso de Sistemas de Informação, os alunos sentam-se estimulados em aprofundar a prática no uso de lógica, o que reflete positivamente em disciplinas de algoritmos, estrutura de dados e de programação.

Deve-se destacar, também, que a ORL tem se tornado ponto de partida para alunos iniciarem atividades de preparação e posterior participação em Maratonas de Programação.

\section{Referências}

Barros, L. G.; Ribeiro, S. P. S.; Oeiras, J. Y. Y. (2009). Projeto de Extensão Universitária para apoio e realização da Olimpíada Brasileira de Informática em Escolas. In Anais do XVII Workshop sobre Educação em Computação, Congresso anual da SBC 2009. Bento Gonçalves.

Deters, J. I.; Silva, J. M. C.; Miranda, E. M.; Fernandes, A. M. R. (2008). O Desafio de trabalhar com alunos repetentes na disciplina de Algoritmos e Programação. In Anais do II Workshop de Ambientes de apoio à Aprendizagem de Algoritmos e Programação, XIX Simpósio Brasileiro de Informática na Educação 2008. Fortaleza.

Lopes, M. G. (2005). Jogos na Educação: criar, fazer, jogar. São Paulo: Cortez.

Savi1, R.; Ulbricht, V. R. (2008). Jogos digitais educacionais: benefícios e desafios. Revista Novas Tecnologias na Educação, Porto Alegre: UFRGS. Vol. 6 No 2. Dezembro, 2008.

Tarouco, L. M. R.; Roland, L. C.; Fabre, M. J. M.; Konrath, M. L. P. (2004). Jogos educacionais. Revista Novas Tecnologias na Educação, Porto Alegre: UFRGS. Vol. $2 \mathrm{~N}^{\mathrm{o}}$ 1. Março, 2004.

UNICAMP (2015). Olimpíada Brasileira de Informática. Disponível em http://olimpiada.ic.unicamp.br/info/geral/regulamento.

USP (2015). Maratona de Programação. Disponível em http://maratona.ime.usp.br. 